\title{
Suicide in Birmingham
}

\author{
CHRISTINE HASSALL， W. H. TRETHOWAN
}

British Medical fournal, 1972, 1, 717-718

\section{Summary}

The number of deaths from suicide in the City of Birmingham has fallen dramatically over the past eight years. Investigation shows that this seems to be wholly due to a reduction in deaths due to domestic coal-gas.

\section{Introduction}

The purpose of this paper is to examine the sharp decline in the suicide rate in the City of Birmingham during the years 1963-70. While it might be supposed that this decline is a result of prompter identification of those at risk and the earlier instigation of more effective methods of treatment analysis of the problem fails to confirm this.

\section{Procedure}

The suicide record cards in the City of Birmingham Coroner's office for the decade 1961-70 were scrutinized and the following data extracted: sex, age, and abode; date of attempt; and method of committing suicide. The methods used were divided into three categories: (1) relatively passive and slowacting methods-that is, taking tablets such as barbiturates, anticonvulsants, and antidepressive, tranquillizing, and other psychotropic drugs; (2) domestic coal-gas however administered; and (3) relatively more active and violent methods such as hanging, leaping, drowning, and self-laceration; also included in this category are corrosive poisons and a very small number of subjects using car exhaust gas, which involves fairly elaborate preparation. All these methods are characterized by a high degree of probability that using them is likely to cause death or at least severe injury.

\section{Results}

The numbers of suicides in the City of Birmingham during the years 1950-70 are shown in Fig. 1. Apart from a peak reached in 1957, due to an exceptionally large number of male suicides, the total rate remained fairly constant until 1963, when it began to decline and continued to do so almost constantly thereafter. This is true of both sexes. The number of male suicides fell from 78 in 1963 to 38 in 1970, a decline of $51 \%$, while the female rate during the same period fell from 66 to 26 , a decline of $61 \%$. The annual suicide rate for males always exceeds that for females, the ratio, as a general rule, being around $6: 5$.

The number of suicides during the decade 1951-70 is shown in Fig. 2 according to method. It is immediately apparent that there is a highly significant drop in the number of deaths from domestic coal-gas (method 2) from 87 in 1962 to 12 in $1970(P<0.001)$. In contrast the rate of suicide by tablet-taking (method 1) does not vary significantly over this

Department of Psychiatry, University of Birmingham, Birmingham B15 2TJ

CHRISTINE HASSALL, M.SC., PH.D., Senior Research Associate W. H. TRETHOWAN, F.R.C.P., F.R.C.PSYCH., Professor of Psychiatry period $(P>0 \cdot 10)$. While there is a slight rise in suicides due to violent means (method 3 ) this, on further analysis, turns out to be due to a small but significant increase in the use of such methods by male subjects only $(P<0.02)$, whereas in females the rate remains remarkably constant (see Fig. 3).

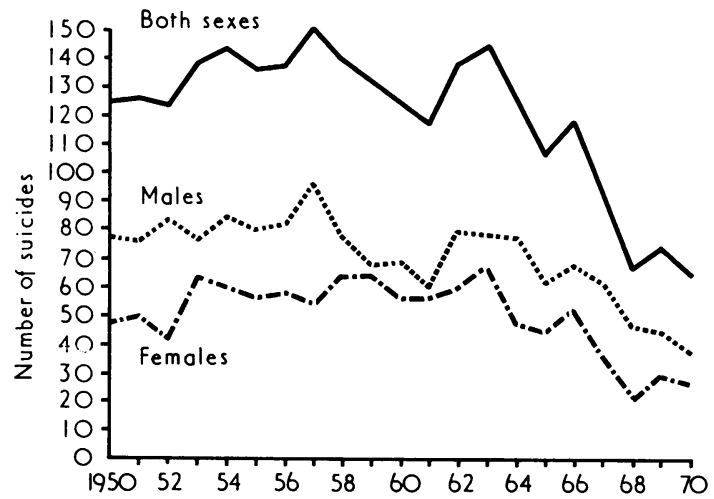

FIG. 1-Number of suicide deaths in Birmingham, 1950-70.

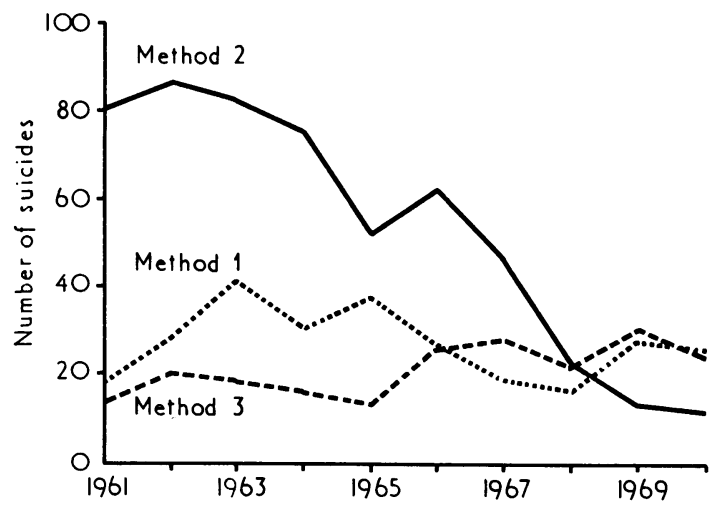

FIG. 2-Number of suicide deaths from methods 1,2 , and 3 , 1961-70.

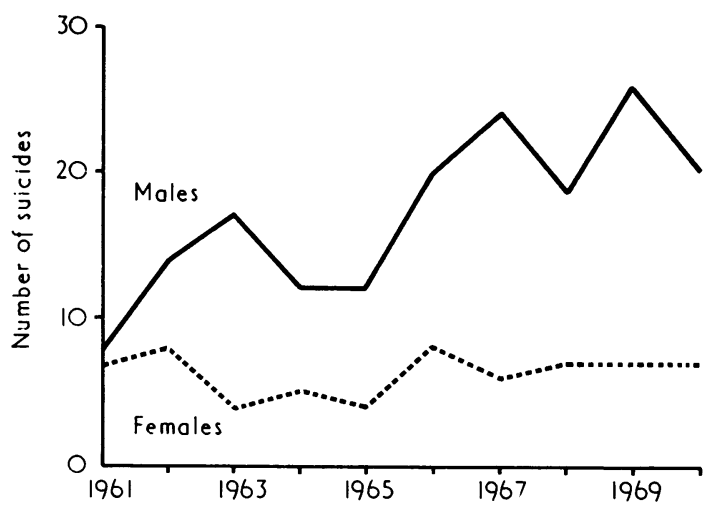

FIG. 3-Number of suicides using method 3 (violent methods), 1961-70. 
Taken as a whole women resorted to coal-gas less often than men (see Fig. 4). In 1961 of all males who committed suicide 45 used coal-gas $(75 \%)$. With small fluctuations this number fell until, in 1969 , it was only $8(18 \%)$, though the number rose very slightly in the following year. In women coal-gas suicides accounted for 36 deaths in 1961 (64\% of all female suicides). In 1970 only two women committed suicide by this means $(8 \%)$.

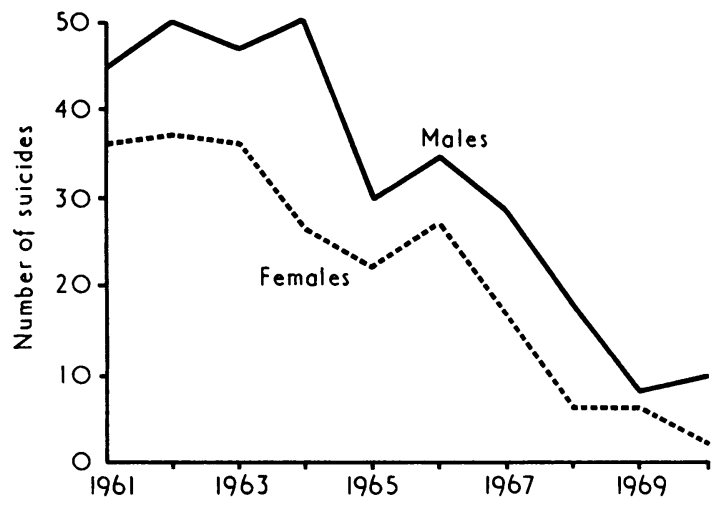

FIG. 4-Number of deaths from suicide by coal-gas poisoning (method 2), 1961-70.

Further analysis of the data extracted from the records adds very little to these findings. Both sexes show a reduction in the proportion committing suicide of those aged 65 years and over without regard to method.

\section{Discussion}

According to the Registrar-General's statistics the suicide rate in England and Wales fell over the period 1963-9 (figures for 1970 are not yet available) from 120 to 89 per million population, a fall of $26 \%$. In Birmingham the decline per million population over the same period was from 122 to 67 per million population, a fall of $45 \%$, almost double that of the fall in the suicide rate in the whole country. Because, as has been shown, the decline in Birmingham's suicide rate is wholly due to a dramatic drop in coal-gas deaths and not due to a proportionate fall in the use of other methods, this at once indicates that would-be suicides are either no longer having recourse to domestic coal-gas in the same proportion as they once did or else that the method has become a progressively less efficient means of suicide.

The last decade has seen the instigation in the City of Birmingham of a very extensive rehousing programme. Contrary perhaps to expectation the number of gas appliances installed in new houses and flats has not fallen but, according to the West Midlands Gas Board, has actually increased. Thus there has been no decline in the availability of domestic gas supply.

Although Birmingham's gas supply has not been converted to natural (North Sea) gas an alteration in gas-making feed- stocks has reduced the average carbon monoxide content over the past seven years from about $20 \%$ to $2.5 \%$. It is, therefore, the drop in the toxic $\mathrm{CO}$ content of domestic gas which seems to account for the fall in gas suicide deaths. This conclusion would seem further to be confirmed by a similar fall over the same period in the number of accidental deaths due to coal-gas (Fig. 5).

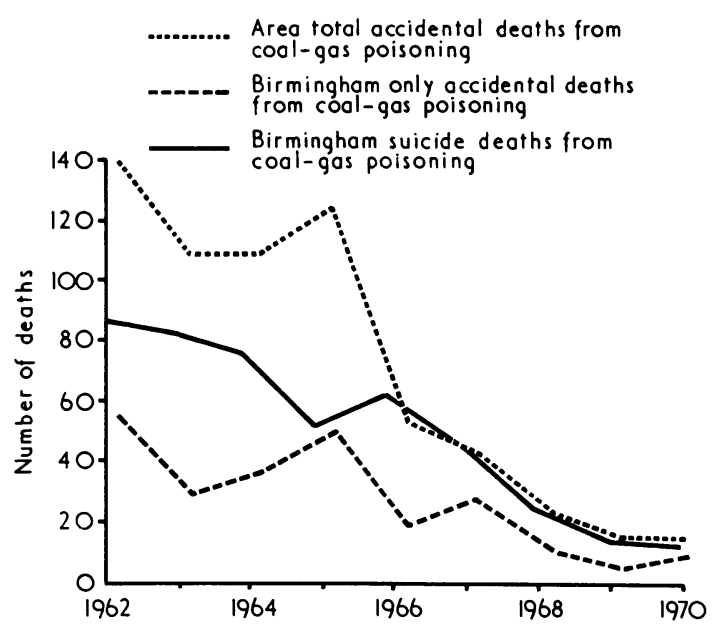

FIG. 5-Accidental deaths from coal-gas poisoning in West Midlands Area and Birmingham only; suicide deaths from coal-gas poisoning in Birmingham, 1962-70.

It is interesting to speculate what happens to those who attempt suicide by coal-gas who in the past might well have succeeded but who nowadays are likely to fail. It would seem that some men may have recourse to violent methods instead, as there appears to be a small but significant rise in the number of such suicides. It is possibly more likely that having failed with gas some male and rather more female would-be suicides may have recourse to sleeping tablets, etc. However, there can be no certainty about this as there has been only an insignificant rise in the number of either sex committing suicide by this means. At the same time this cannot be taken to imply that many more may not have attempted unsuccessfully to commit suicide by taking tablets, for, in recent years, resuscitation after self-poisoning has become much more efficient. Because of this the finding that the number who die after taking tablets has not fallen may well be indicative to the fact that the number of those who attempt to do so unsuccessfully has indeed risen. The experience of most casualty departments, both in the City of Birmingham and elsewhere, of a growing number of selfpoisoning cases strongly suggests that this is so. This, however, is a matter requiring further investigation.

We are grateful to Mr. G. Billington the City Coroner both for drawing attention to the decline in the suicide rate in the City of Birmingham and for allowing access to his records, and to the Secretary of the West Midlands Gas Board for supplying data in regard to the composition of domestic coal-gas and for figures relating to accidental deaths due to gas. 